\title{
Período Crítico de Interferência das Plantas Daninhas na Cultura do Milho Baseado na Fenologia da Cultura ${ }^{1}$
}

\author{
Critical Period of Weed Interference in Corn Crop Based on Crop Phenology
}

\author{
KOZLOWSKI, L.A. ${ }^{2}$
}

\begin{abstract}
RESUMO - No ano agrícola 2000/2001 foi conduzido, na Fazenda Experimental Gralha Azul/ PUCPR, um experimento de campo com o objetivo de determinar o período crítico para prevenção da interferência das plantas daninhas sobre a cultura do milho, determinado com base na fenologia da cultura. O delineamento experimental utilizado foi o de blocos ao acaso em arranjo fatorial $2 x 7$, com quatro repetições. Os 14 tratamentos testados foram resultados da combinação de duas séries de tratamentos: com a cultura em períodos iniciais de crescimento em competição com as plantas daninhas, e com a cultura em períodos iniciais de crescimento sem competição; estes períodos iniciais foram caracterizados por estádios fenológicos da cultura do milho $-\mathrm{V}_{2}, \mathrm{~V}_{4}, \mathrm{~V}_{6}, \mathrm{~V}_{8}$ e $\mathrm{V}_{10}$ - e duas testemunhas. O experimento foi instalado em uma área sob plantio direto, com semeadura realizada de acordo com a tecnologia recomendada para a cultura, com adubações no sulco e em cobertura e tratamentos fitossanitários, para que as plantas de milho se desenvolvessem normalmente. O período crítico de prevenção da interferência ocorreu entre os estádios fenológicos $\mathrm{V}_{2}$ e $\mathrm{V}_{7}$, e a interferência das plantas daninhas reduziu em média $87 \%$ o rendimento de grãos da testemunha em competição durante todo o ciclo da cultura em relação à testemunha sem competição com as plantas daninhas, por todo o ciclo. Com relação à comunidade infestante, as dicotiledôneas representaram 22,3\% das plantas daninhas, destacando-se as espécies Taraxacum officinale, Senecio brasiliensis, Rumex obtusifolius e Bidens pilosa, e as monocotiledôneas, $77,7 \%$ da comunidade infestante, com destaque para Brachiaria plantaginea. O acúmulo de biomassa seca das plantas de milho, a população final e o número de espigas por planta não foram afetados pela interferência das plantas daninhas.
\end{abstract}

Palavras-chave: milho, fenologia, interferência, período crítico, plantio direto.

\begin{abstract}
A field experiment was carried out to determine the critical period of weed interference in corn, under a no-tillage system, based on the phenological stage of corn crop growth, at the Gralha Azul Experimental Farm/PUC PR - Brazil, during the growing season of 2000/2001. The experimental design was a randomized complete block arranged in a $2 x 7$ factorial, with four replications. The fourteen treatments evaluated resulted from two series of treatments: with the crop weed free during the initial crop development and with the crop weedy during the initial crop development, in five phenological stages of corn crop growth: $V_{2}, V_{4}, V_{6}, V_{8}$ and $V_{10}$ and two checks. The experiment was carried out on an area under no-till system. Seeding, fertilization, and insect and disease control were conducted according to crop technology. Weed interference critical period was between $V_{2}$ and $V_{7}$ phenological stages of growth, and corn yield was reduced in $87 \%$ when the crop was kept weedy during all the cycle, compared to the weed free crop. The dicotyledon species represented $22.3 \%$ of the community, with Taraxacum officinale, Senecio brasiliensis, Rumex obtusifolius and Bidens pilosa being most prevalent. Monocotyledons species represented $77.7 \%$, and Brachiaria plantaginea was the most prevalent. Biomass accumulation of corn, final population and ear per plant were not affected by weed interference.
\end{abstract}

Key words: corn, phenology, interference, critical period, no-till.

Recebido para publicação em 25/3/2002 e na forma revisada em 9/12/2002.

Professor Adjunto, M.S., Pontifícia Universidade Católica do Paraná, Curitiba-PR, <kozlowsk@rla01.pucpr.br>. 


\section{INTRODUÇÃO}

O milho (Zea mays) é considerado uma das principais espécies utilizadas no mundo, ocupando no Brasil cerca de 13 milhões de hectares, porém a cultura ainda apresenta baixo rendimento, devido a inúmeros fatores, dentre os quais certamente a interferência exercida pela presença de plantas daninhas assume grande importância.

A redução do rendimento da cultura devido à competição estabelecida com as plantas daninhas pode variar de 12 até 100\% (Almeida, 1981; Blanco et al., 1976), em função da espécie, do grau de infestação, do tipo de solo, das condições climáticas reinantes no período, além do estádio fenológico da cultura. Esse fato foi confirmado em ensaio de campo, onde se verificou que, a partir da emissão da quinta folha, a presença de plantas daninhas na cultura do milho reduziu o rendimento de grãos, comprimento médio da espiga e número médio de grãos por fileira (Fancelli \& Dourado Neto, 2000).

O grau de interferência normalmente é medido com relação à produção da planta cultivada e pode ser definido como a redução percentual da produção econômica de determinada cultura, provocada pela interferência da comunidade infestante (Pitelli, 1985). O grau de interferência depende de características da cultura, como variedade ou espécie, espaçamento e densidade de plantio; de características da comunidade infestante, como composição específica, densidade e distribuição; de características do ambiente, referentes às condições edáficas, climáticas e de manejo do sistema agrícola; e da época e duração do período de convivência entre planta daninha e cultura (Bleasdale, 1960).

De todos os fatores que influenciam o grau de interferência, o mais importante é o período em que a comunidade infestante e as plantas cultivadas estão disputando os recursos do meio (Pitelli, 1985), período este denominado período crítico de prevenção da interferência (PCPI), no qual o controle da vegetação infestante realmente é crítico, ou seja, antes que a comunidade infestante interfira na produtividade ou em outra característica da cultura até a época em que doravante não mais a influenciará (Pitelli \& Durigan, 1984).
O período crítico de competição é o período de tempo em que medidas de controle são necessárias para evitar a continuidade da interferência entre a cultura e as plantas daninhas, evitando perdas no rendimento. Entretanto, esse período deve ser considerado um estádio de desenvolvimento da cultura em relação às plantas daninhas e não como um período de tempo definido (Radosevich \& Holt, 1984).

A utilização prática da fenologia é assegurada por inúmeros estudos que permitem o estabelecimento de correlações entre a ocorrência de eventos fisiológicos e bioquímicos na planta com seus aspectos morfológicos, como número e tipos de folhas, presença de estruturas reprodutivas e frutos, oferecendo maior segurança e precisão nas ações de manejo e de pesquisa. Portanto, a continuidade da geração de informações e de recomendações de manejo, notadamente no que concerne à avaliação do período crítico de interferência, fundamentado em escala de dias após a emergência, muito pouco acrescenta para a elucidação do problema, além de contribuir para conclusões equivocadas e de validade científica duvidosa (Fancelli \& Dourado Neto, 2000).

As recomendações de manejo para a cultura do milho baseadas em escala de tempo com certeza têm contribuído para a redução da eficiência no uso de insumos e defensivos, especialmente herbicidas, como também tem ocasionado equívocos na preservação de etapas importantes de definição de produção e rendimento por parte da planta. Assim, visando o desenvolvimento de uma agricultura mais tecnificada e científica, torna-se imprescindível o emprego de conhecimentos de fenologia, o que permite avaliar o grau de influência dos fatores envolvidos na produção, bem como estabelecer estratégias de manejo condizentes com os estádios de desenvolvimento da planta.

Na cultura do milho, vários autores estudaram o período crítico de competição, entre eles Beckett et al. (1988), Hall et al. (1992), Ramos \& Pitelli (1994) e Wilson \& Westra (1991), porém esses trabalhos forneceram informações do período crítico de competição com base em um período de tempo definido, ou seja, dias após a emergência, ao passo que poucos autores, como Defelice (2001), estudaram o período crítico de competição com base em uma escala 
fenológica da cultura em relação às plantas daninhas.

O presente trabalho teve como objetivo determinar o período crítico de prevenção da interferência das plantas daninhas sobre a cultura do milho em sistema de semeadura direta, associando este período com a fenologia da planta.

\section{MATERIAL E MÉTODOS}

O trabalho experimental de campo foi instalado e conduzido no ano agrícola de 2000/ 01 na Fazenda Experimental Gralha Azul, da Pontifícia Universidade Católica do Paraná, município de Fazenda Rio Grande-PR. A região, segundo a classificação de Koëpen, apresenta clima do tipo $\mathrm{Cfb}$ e solo pertencente à unidade de mapeamento associação Latossolo Vermelho-Amarelo Álico + Cambissolo Álico, com horizonte A proeminente, textura argilosa, fase subtropical, relevo suave ondulado.

O experimento foi instalado em uma área sob plantio direto, tendo a aveia preta como cobertura. A semeadura do milho foi realizada em 4 de outubro de 2000, após o manejo químico da aveia, utilizando-se o híbrido C909, a adubação de $350 \mathrm{~kg} \mathrm{ha}^{-1}$ do formulado 10-20-20 e demais práticas culturais de acordo com a tecnologia recomendada para a cultura (EMBRAPA, 1998).

A parcela experimental foi composta por quatro linhas espaçadas entre si de $0,80 \mathrm{~m}$ e $7,0 \mathrm{~m}$ de comprimento, perfazendo $22,40 \mathrm{~m}^{2}$ de área total. Para fins de avaliação foram consideradas como área útil das parcelas experimentais as duas linhas centrais com $6,50 \mathrm{~m}$ de comprimento, desprezando-se $0,25 \mathrm{~m}$ a título de bordadura, na frente e no fundo de cada parcela, totalizando $10,40 \mathrm{~m}^{2}$.

O delineamento experimental utilizado foi o de blocos ao acaso com tratamentos em arranjo fatorial $2 \times 7$, com quatro repetições. Os tratamentos foram separados em dois modelos de interferência das plantas daninhas: no primeiro, inicialmente sujo (S), a cultura conviveu com a comunidade infestante por períodos crescentes; e, no segundo, inicialmente limpo (L), a cultura foi submetida a períodos crescentes de controle da comunidade infestante. Ambos os modelos de interferência foram aplicados em diferentes estádios fenológicos de desenvolvimento do milho: $V_{2}$, $\mathrm{V}_{4}, \mathrm{~V}_{6}, \mathrm{~V}_{8}$ e $\mathrm{V}_{10}$, ou seja, 2, 4, 6, 8 e 10 folhas totalmente expandidas (Ritchie et al., 1993) e mais duas testemunhas com todo o ciclo, no limpo e no mato, conforme apresentado na Tabela 1.

Tabela 1 - Descrição dos tratamentos experimentais. Fazenda Experimental Gralha Azul/PUCPR, Fazenda Rio GrandePR. 2000/01

\begin{tabular}{|c|c|c|}
\hline Tratamento & $\begin{array}{c}\text { Período de convivência } \\
\text { (dias) }\end{array}$ & $\begin{array}{c}\text { Período de controle } \\
\text { (dias) }\end{array}$ \\
\hline 1 & 0 & $\ldots \ldots$ \\
2 & $0-\mathrm{V}_{2}$ & $\ldots \ldots$ \\
3 & $0-\mathrm{V}_{4}$ & $\ldots \ldots$ \\
4 & $0-\mathrm{V}_{6}$ & $\ldots \ldots$ \\
5 & $0-\mathrm{V}_{8}$ & $\ldots \ldots$. \\
6 & $0-\mathrm{V}_{10}$ & $\ldots \ldots$ \\
7 & $0-$ colheita & $\ldots \ldots$. \\
8 & $\ldots \ldots$. & 0 \\
9 & $\ldots \ldots$. & $0-\mathrm{V}_{2}$ \\
10 & $\ldots \ldots$. & $0-\mathrm{V}_{4}$ \\
11 & $\ldots \ldots$. & $0-\mathrm{V}_{6}$ \\
12 & $\ldots \ldots$. & $0-\mathrm{V}_{8}$ \\
13 & $\ldots \ldots$. & $0-\mathrm{V}_{10}$ \\
14 & $\ldots \ldots$. & $0-$ colheita \\
\hline
\end{tabular}

Tratamentos 1 - 7: inicialmente sujo.

Tratamentos 8-14: inicialmente limpo.

A remoção das plantas daninhas ao final de cada período de convivência inicial, bem como a manutenção dessas parcelas livres da presença das plantas daninhas até o final do ciclo da cultura, foi realizada mediante o uso de um pulverizador costal, com bico centrífugo rotativo e proteção lateral para aplicação em jato dirigido às entrelinhas, usando uma calda de paraquat (200 g i.a. $\mathrm{L}^{-1}$ ) a $3 \%$. Os períodos crescentes de controle também foram obtidos com freqüentes operações de pulverização em jato dirigido às entrelinhas, conforme descrito anteriormente, que eram interrompidas à medida que se atingia cada um dos diferentes estádios fenológicos do milho.

Foi feita a coleta, ao acaso, de seis plantas de milho nas duas linhas laterais externas à área útil, em cada uma das parcelas experimentais, com três plantas em cada linha, em cada um dos diferentes estádios de desenvolvimento do milho: $2,4,6,8$ e 10 folhas 
totalmente expandidas, tanto no modelo inicialmente sujo como no inicialmente limpo, com posterior secagem das plantas em estufa de circulação forçada de ar a $70{ }^{\circ} \mathrm{C}$ até peso constante, para posterior determinação da biomassa aérea seca. Os dados obtidos foram transformados em $\log x$, para uniformização dos valores, e ajustados a um modelo de regressão não-linear, para melhor descrever o acúmulo de biomassa pela cultura.

Nas parcelas com a convivência inicial entre a cultura e a comunidade infestante (inicialmente sujas), foi realizada a coleta, contagem e identificação das espécies de plantas daninhas presentes em uma área central de $0,25 \mathrm{~m}^{2}$, ao final de cada período de convivência, para determinação da composição específica da comunidade infestante, em porcentagem e densidade de indivíduos das populações de plantas daninhas presentes, corrigindo a densidade para número de plantas por $\mathrm{m}^{2}$, em cada um dos diferentes estádios de desenvolvimento do milho. Posteriormente foi feita a secagem das plantas daninhas em estufa de circulação forçada de ar a $70{ }^{\circ} \mathrm{C}$ até peso constante, para determinação da biomassa aérea seca acumulada, extrapolando os valores para gramas de matéria seca por $\mathrm{m}^{2}$.

No final do ciclo da cultura do milho, realizou-se a colheita das espigas presentes na área útil das parcelas experimentais. Contou-se o número de plantas e espigas de cada parcela, obtendo, assim, a população e o índice de espigas. O material colhido foi debulhado e pesado, sendo os valores corrigidos para $13 \%$ de umidade e transformados em $\mathrm{kg} \mathrm{ha}^{-1}$.

Para determinação do período crítico de prevenção da interferência (PCPI), os dados dos rendimentos obtidos nos diferentes estádios fenológicos, em ambos os modelos de interferência, foram ajustados a um modelo de regressão não-linear, por meio do programa TableCurve, usando o seguinte modelo logístico:

$$
y=\frac{a}{\left[1+\left(\frac{x}{b}\right)^{c}\right]}
$$

em que $y$ é rendimento de grãos; $x$ é número de dias após a emergência da cultura; e $a, b$ e $c$ são coeficientes, de modo que $a$ é o rendimento máximo, obtido na testemunha limpa, $b$ é o número de dias em que ocorre $50 \%$ de redução no rendimento máximo e $c$ é a declividade da curva. A opção pela equação logística é pelo fato de que todos os componentes da equação apresentam significado biológico, conforme descrito anteriormente, o que permite a determinação do período crítico de prevenção da interferência.

O início do período crítico de prevenção da interferência, identificado pelo final do período anterior à interferência (PAI) no modelo inicialmente sujo, foi calculado subtraindo-se a diferença mínima significativa (LSD a $5 \%$ de probabilidade) da média do rendimento máximo. O resultado foi substituído em $y$ da equação logística, obtendo-se assim o valor de $x$, que identifica o número de dias ou estádio fenológico após a emergência do milho em que se iniciou o período crítico de prevenção da interferência.

O final do período crítico de prevenção da interferência, coincidente com o final do período total de prevenção da interferência (PTPI) no modelo inicialmente limpo, foi calculado subtraindo-se a diferença mínima significativa (LSD a 5\% de probabilidade) da média do rendimento máximo. O resultado foi substituído em y da equação logística, obtendo-se, dessa forma, o valor de $x$, que identifica o número de dias ou estádio fenológico após a emergência do milho em que terminou o período crítico de prevenção da interferência.

Todos os dados obtidos no experimento foram submetidos à análise de variância, utilizando-se o programa estatístico MSTATC. As variáveis cujas variâncias se mostraram homogêneas tiveram seus tratamentos analisados por meio do teste $\mathrm{F}$, e as médias foram comparadas pelo teste LSD a $5 \%$ de probabilidade.

\section{RESULTADOS E DISCUSSÃO}

Na Tabela 2 está representado o número de dias após a emergência do milho em que foram caracterizados os cinco estádios fenológicos $\left(\mathrm{V}_{2}\right.$ a $\left.\mathrm{V}_{10}\right)$ e a colheita do milho. $\mathrm{Na}$ Figura 1, observam-se as temperaturas médias, máximas e mínimas mensais que ocorreram durante o ciclo do milho, e este, por ser 
termossensivel, tem sua fenologia influenciada pela temperatura; assim, verifica-se que nos primeiros 60 dias do ciclo vegetativo as temperaturas foram iguais ou inferiores a $25 \mathrm{e}$ $14{ }^{\circ} \mathrm{C}$, para médias máxima e mínima, respectivamente, fazendo com que a duração de cada um dos estádios fenológicos vegetativos tenha sido um pouco mais longa do que o normal.

Tabela 2 - Dias após a emergência (DAE) do milho em que foram caracterizados os cinco estádios fenológicos $\left(\mathrm{V}_{2}\right.$ a $\mathrm{V}_{10}$ ) e a colheita. Fazenda Experimental Gralha Azul/ PUCPR, Fazenda Rio Grande-PR. 2000/01

\begin{tabular}{|c|c|}
\hline Estádio fenológico & DAE \\
\hline $\mathrm{V}_{2}$ & 15 \\
$\mathrm{~V}_{4}$ & 27 \\
$\mathrm{~V}_{6}$ & 35 \\
$\mathrm{~V}_{8}$ & 53 \\
$\mathrm{~V}_{10}$ & 66 \\
Colheita & 137 \\
\hline
\end{tabular}

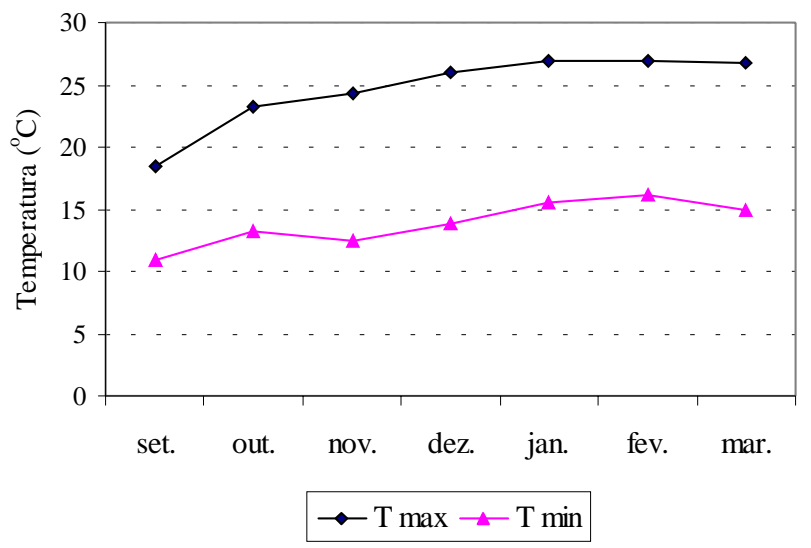

Figura 1 - Temperaturas médias, máximas e mínimas mensais, observadas durante o ciclo da cultura de milho. FEGA/ PUCPR, Fazenda Rio Grande-PR. 2000/01.

Os resultados de rendimento do milho podem ser analisados observando-se a Figura 2, onde, comparando as produtividades obtidas na ausência total das plantas daninhas (testemunha limpa) com as obtidas na presença destas durante todo o ciclo (testemunha suja), se verifica que a redução média no rendimento foi de $87 \%$. A produtividade do milho obtida na ausência das plantas daninhas durante todo o ciclo foi de $8.568 \mathrm{~kg} \mathrm{ha}^{-1}$ e decaiu para $1.130 \mathrm{~kg} \mathrm{ha}^{-1}$ quando ocorreu a presença das infestantes durante todo o ciclo.
Esses resultados concordam com trabalhos anteriores, em que se constatou redução no rendimento de grãos devido à interferência das plantas daninhas (Almeida, 1981; Blanco et al., 1976).

Na Figura 2 estão representadas as duas curvas de regressão não-linear ajustadas, uma representando os rendimentos obtidos no modelo com convivência inicial (sujo), que foi o período anterior à interferência (PAI), e a outra representando os rendimentos obtidos no modelo com controle inicial (limpo), que é o período total de prevenção da interferência (PTPI). Comparando as médias dos tratamentos, pelo teste LSD a 5\% de probabilidade, dentro do mesmo modelo de interferência, ou seja, sujo ou limpo, observa-se que o valor da diferença mínima significativa $(\mathrm{P}<0,05)$ foi de $709 \mathrm{~kg} \mathrm{ha}^{-1}$, o que permite inferir que rendimentos iguais ou superiores a $7.859 \mathrm{~kg} \mathrm{ha}^{-1}$ (8.568 - 709), para os modelos sujo e limpo, não diferem significativamente, sendo dessa forma possível calcular o período crítico de prevenção da interferência (PCPI) a partir do modelo logístico.

Assim, verifica-se que o período anterior à interferência ocorreu da emergência da cultura do milho até o estádio fenológico de 2 folhas $\left(\mathrm{V}_{2}\right)$, ao passo que o período total de prevenção da interferência ocorreu da emergência do milho até o estádio de 7 folhas $\left(\mathrm{V}_{7}\right)$, de modo que o período crítico de prevenção da interferência corresponde ao período compreendido entre os estádios fenológicos de $2\left(\mathrm{~V}_{2}\right)$ a $7\left(\mathrm{~V}_{7}\right)$

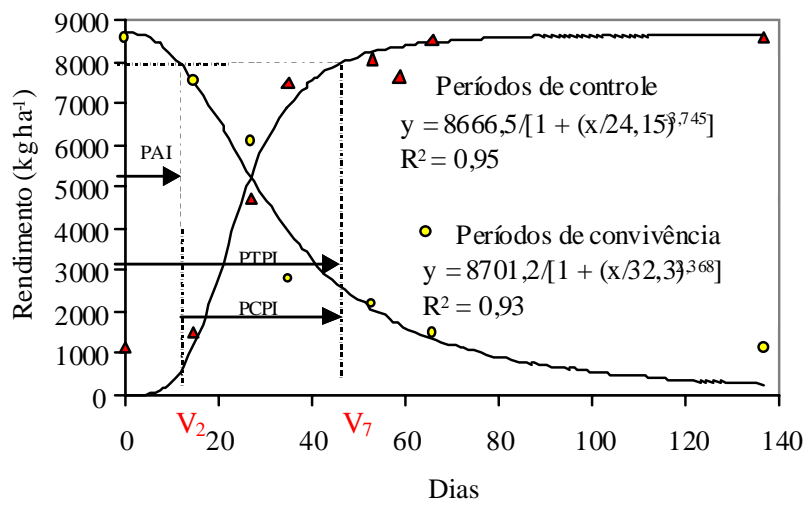

Figura 2 - Rendimento de grãos do milho, em função dos períodos de convivência e de controle das plantas daninhas na área experimental. FEGA/PUCPR, Fazenda Rio GrandePR. 2000/01. 
folhas totalmente expandidas. Portanto, para obter os máximos rendimentos é necessário que a cultura fique na ausência das plantas daninhas durante esse período de tempo. Resultados obtidos em outros trabalhos indicaram que o período crítico de prevenção da interferência ocorreu entre os estádios fenológicos $\mathrm{V}_{2} / \mathrm{V}_{3}$ até $\mathrm{V}_{12}$ (Defelice, 2001).

Na Figura 3 estão representados graficamente a densidade total das plantas daninhas presentes nas parcelas com convivência inicial e o respectivo acúmulo de biomassa seca em função dos diferentes estádios fenológicos. Verifica-se que o aumento da biomassa seca das plantas daninhas, folhas largas e estreitas, foi progressivo entre os estádios $\mathrm{V}_{2}$ e $\mathrm{V}_{10}$, embora as maiores densidades fossem observadas nos estádios $\mathrm{V}_{2}, \mathrm{~V}_{4} \mathrm{e} \mathrm{V}_{6}$, com média de 525 plantas $\mathrm{m}^{-2}$ (Tabela 3 ). Contudo, as maiores densidades nestes estádios caracterizaram-se por plantas de diferentes tamanhos e estádios de desenvolvimento, devido aos vários fluxos de emergência. À medida que aumentou o crescimento das plantas daninhas, especialmente daquelas que germinaram e emergiram no início do ciclo do milho, intensificou-se a competição inter e intra-específica, de modo que as plantas daninhas mais altas e desenvolvidas tornaram-se dominantes, ao passo que as menores foram suprimidas ou morreram, justificando, assim, a redução da densidade das infestantes com o aumento da biomassa seca das plantas daninhas nos estádios de desenvolvimento finais do milho (Radosevich \& Holt, 1984).



Figura 3 - Densidade total e biomassa seca das plantas daninhas ao final dos períodos de convivência com o milho nos diferentes estádios fenológicos. FEGA/PUCPR, Fazenda Rio Grande-PR. 2000/01.
De acordo com a Tabela 3, a maior densidade de plantas daninhas (676 plantas $\mathrm{m}^{-2}$ ) ocorreu no estádio $\mathrm{V}_{2}$, início do período crítico de prevenção da interferência, mantendo-se alta (404 plantas $\mathrm{m}^{-2}$ ) até próximo do final do período de competição, no estádio $\mathrm{V}_{6}$. Observase, na Tabela 4, que as dicotiledôneas representam $22,3 \%$ da comunidade infestante, destacando-se as espécies Taraxacum officinale, Senecio brasiliensis, Rumex obtusifolius e Bidens pilosa, com 8,36; 5,84; 4,18; e 3,16\%, respectivamente. Já as monocotiledôneas representam $77,7 \%$ da comunidade infestante, com destaque e predominância da espécie Brachiaria plantaginea. Essas cinco espécies corresponderam a 99,3\% dos indivíduos da comunidade infestante.

Na Figura 4 estão representadas as curvas ajustadas (sujo ajs e limpo ajs) de acúmulo de biomassa seca do milho, quando submetido a períodos de controle inicial e convivência inicial com as plantas daninhas. Verifica-se que os diferentes modelos de interferência não influenciaram o acúmulo de biomassa do milho, durante os estádios fenológicos avaliados, não ocorrendo diferenças significativas entre eles. Esses resultados discordam dos obtidos por Rossi et al. (1996), que constataram redução de 26 e $39 \%$ no acúmulo de biomassa seca de folhas e colmos, respectivamente, a partir dos 35 dias após a semeadura, enquanto para biomassa seca das bainhas das folhas a redução foi de 23\%, a partir dos 49 dias após a semeadura, devido à interferência das plantas daninhas.

Na Tabela 5 pode-se observar o efeito dos períodos de convivência da comunidade infestante sobre a população final de plantas e o indice de espigas na cultura do milho. Analisando os resultados, observa-se que a interferência das plantas daninhas não influenciou negativamente nenhuma das variáveis estudadas. Resultados semelhantes foram obtidos por Rossi et al. (1996) e Ramos \& Pitelli (1994), que também não verificaram redução no número de espigas por planta e na população final do milho em razão da interferência das plantas daninhas. No entanto, Zagonel et al. (2000) constataram que a população e o número de espigas por planta diminuíram com o atraso na época de controle, em conseqüência da matocompetição. 
Tabela 3 - Composição específica e densidade (plantas $\mathrm{m}^{-2}$ ) das plantas daninhas presentes nas parcelas com convivência inicial com a cultura do milho. FEGA/PUCPR, Fazenda Rio Grande-PR. 2000/01

\begin{tabular}{|c|c|c|c|c|c|}
\hline \multirow{2}{*}{ Composição específica } & \multicolumn{5}{|c|}{ Estádio fenológico } \\
\hline & $\mathrm{V}_{2}$ & $\mathrm{~V}_{4}$ & $\mathrm{~V}_{6}$ & $\mathrm{~V}_{8}$ & $\mathrm{~V}_{10}$ \\
\hline Solanum sisymbrifolium & 8 & 0 & 0 & 0 & 0 \\
\hline Rumex obtusifolius & 0 & 32 & 32 & 12 & 4 \\
\hline Taraxacum officinale & 0 & 40 & 0 & 42 & 28 \\
\hline Ipomoea spp. & 0 & 12 & 0 & 0 & 0 \\
\hline Bidens pilosa & 0 & 24 & 24 & 0 & 8 \\
\hline Senecio brasiliensis & 0 & 0 & 44 & 32 & 12 \\
\hline Subtotal (1) & 8 & 108 & 100 & 92 & 92 \\
\hline Brachiaria plantaginea & 668 & 388 & 304 & 204 & 108 \\
\hline Subtotal (2) & 668 & 388 & 304 & 204 & 108 \\
\hline Total $(1+2)$ & 676 & 496 & 404 & 296 & 160 \\
\hline
\end{tabular}

Tabela 4 - Composição percentual das populações de plantas daninhas presentes nas parcelas com convivência inicial com a cultura do milho. FEGA/PUCPR, Fazenda Rio Grande-PR. 2000/01

\begin{tabular}{|l|l|l|l|l|r|r|}
\hline \multirow{2}{*}{ Composição específica } & \multicolumn{7}{c|}{ Estádio fenológico } & \multirow{2}{*}{ Média } \\
\cline { 2 - 7 } & $\mathrm{V}_{2}$ & $\mathrm{~V}_{4}$ & $\mathrm{~V}_{6}$ & $\mathrm{~V}_{8}$ & $\mathrm{~V}_{10}$ & \\
\hline Solanum sisymbrifolium & 1,2 & 0 & 0 & 0 & 0 & 0,24 \\
Rumex obtusifolius & 0 & 6,46 & 7,92 & 4,05 & 2,5 & 4,18 \\
Taraxacum officinale & 0 & 8,06 & 0 & 16,22 & 17,5 & 8,36 \\
Ipomoea spp. & 0 & 2,42 & 0 & 0 & 0 & 0,48 \\
Bidens pilosa & 0 & 4,84 & 5,94 & 0 & 5,0 & 3,16 \\
Senecio brasiliensis & 0 & 0 & 10,89 & 10,81 & 7,5 & 5,84 \\
\hline Subtotal (1) & 1,2 & 21,78 & 24,75 & 31,08 & 32,5 & 22,26 \\
\hline Brachiaria plantaginea & 98,8 & 78,22 & 75,25 & 68,92 & 67,5 & 77,74 \\
\hline Subtotal (2) & 98,8 & 78,22 & 75,25 & 68,92 & 67,5 & 77,74 \\
\hline Total (1 + 2) & 100 & 100 & 100 & 100 & 100 & 100 \\
\hline
\end{tabular}



- sujo $\Delta$ limpo - sujo (ajs) - limpo (ajs)

Figura 4 - Acúmulo de biomassa seca do milho (seis plantas) ao final dos diferentes períodos de controle inicial e convivência inicial. FEGA/PUCPR. Fazenda Rio GrandePR. 2000/01.
Pelos resultados obtidos, verificou-se que o período em que a cultura do milho e as plantas daninhas podem conviver antes que a interferência se instale de maneira a reduzir significativamente a produção (PAI) vai até o estádio $\mathrm{V}_{2}$, sendo teoricamente o final do PAI a época ideal para o primeiro controle das infestantes. Contudo, na prática esse período não pode ser considerado, pois a cultura e/ou as plantas daninhas podem ter atingido um estádio de desenvolvimento que inviabiliza o uso de práticas de controle. Assim, todas as medidas de controle devem ser realizadas no máximo até o estádio fenológico $\mathrm{V}_{2}$.

Da emergência do milho até o estádio $V_{7}$ corresponde ao período em que a cultura deve ficar livre da presença da comunidade 
Tabela 5 - Efeito do período de convivência da comunidade infestante sobre a população (plantas ha ${ }^{-1}$ ) e o índice de espiga (espiga/planta) na cultura do milho. FEGA/ PUCPR, Fazenda Rio Grande-PR. 2000/01

\begin{tabular}{|c|c|c|}
\hline Período de convivência & População & Índice de espiga \\
\hline 0 & 55050 & 0,9 \\
$0-\mathrm{V}_{2}$ & 55225 & 1,0 \\
$0-\mathrm{V}_{4}$ & 55200 & 0,95 \\
$0-\mathrm{V}_{6}$ & 55125 & 0,99 \\
$0-\mathrm{V}_{8}$ & 55125 & 1,0 \\
$0-\mathrm{V}_{10}$ & 55075 & 1,0 \\
$0-$ colheita & 54975 & 0,95 \\
$0-$ colheita & 55000 & 0,95 \\
$\mathrm{~V}_{2}-$ colheita & 55000 & 0,95 \\
$\mathrm{~V}_{4}-$ colheita & 54975 & 1,0 \\
$\mathrm{~V}_{6}-$ colheita & 54975 & 1,0 \\
$\mathrm{~V}_{8}-$ colheita & 54975 & 0,99 \\
$\mathrm{~V}_{10}-$ colheita & 55075 & 1,0 \\
0 & 55000 & 0,9 \\
\hline $\mathrm{F}_{\text {convivencia }}(\mathrm{C})$ & $5,96^{\text {ns }}$ & $0,35^{\text {ns }}$ \\
$\mathrm{F}_{\text {estádio }}(\mathrm{E})$ & $0,45^{\text {ns }}$ & $1,31^{\text {ns }}$ \\
$\mathrm{F}_{\text {CxE }}$ & $0,71^{\text {ns }}$ & $0,81^{\text {ns }}$ \\
CV $(\%)$ & 0,32 & 10,47 \\
d.m.s $(5 \%)$ & 251,8 & 0,15 \\
\hline
\end{tabular}

${ }^{\text {ns }}$ não-significativo.

infestante para que a sua produção não seja influenciada negativamente (PTPI), sendo, na prática, este o período em que as capinas ou o efeito residual dos herbicidas devem abranger, pois as infestantes que emergirem nesse período, em determinada época do ciclo da cultura, terão atingido um estádio de desenvolvimento tal que promoverão interferência, reduzindo significativamente a produção.

\section{LITERATURA CITADA}

ALMEIDA, F. S. Eficácia de herbicidas pós-emergente no controle de plantas daninhas na cultura do milho. In: INSTITUTO AGRONÔMICO DO PARANÁ - IAPAR. Plantio direto no Estado do Paraná. Londrina: 1981. p. 101-144 (Circular, 23).

BECKETT, T. H.; STOLLER, E. W.; WAX, L. M. Interference of four annual weeds in corn (Zea mays). Weed Science, v. 36, n. 4, p. 764-769, 1988.

BLANCO, H. G.; ARAUJO, J. B. M.; OLIVEIRA, D. A. Estudo sobre competição das plantas daninhas na cultura do milho (Zea mays L.), determinação do período de competição. Arquivos do Instituto Biológico, v. 43, p. 105-114, 1976.

Planta Daninha, Viçosa-MG, v.20, n.3, p.365-372, 2002
BLEASDALE, J. K. A. Studies on plant competition. In: HARPER, J. L. (Ed.). The biology of weeds. Oxford: Backwell Scientific Publication, 1960. p. 133-142.

DEFELICE, M. Critical period of weed interference in corn and proper timing of herbicide programs. Disponível em: 2001 (http://www.pioneer.com/usa/crop_management/ national/timing_cornherb.html).

EMPRESA BRASILEIRA DE PESQUISA AGROPECUÁRIA - EMBRAPA. Recomendações técnicas para o cultivo do milho. Brasília, 1998. 204 p.

FANCELLI, L. A.; DOURADO NETO, D. Manejo de plantas daninhas. In: FANCELLI, L.A.; DOURADO NETO, D. (Eds.). Produção de milho. Guaíba: Agropecuária, 2000. p. 183-215.

HALL, M. R.; SWANTON, C. J.; ANDERSON, G. W. The critical period of weed control in grain corn (Zea mays). Weed Science, v. 40, n. 3, p. 441-447, 1992.

PITELLI, R. A. Interferências de plantas daninhas em culturas agrícolas. Informe Agropecuário, v. 11, n. 129, p. 16-27, 1985.

PITELLI, R. A.; DURIGAN, J. C. Terminologia para períodos de controle e de convivência de plantas daninhas em culturas anuais e bianuais. In: CONGRESSO BRASILEIRO DE HERBICIDAS E PLANTAS DANINHAS, 15., Belo Horizonte, 1984. Resumos... Piracicaba: 1984. p. 37.

RADOSEVICH, S. R.; HOLT, J. S. Weed ecology: implications for vegetation management. New York: John Wiley \& Sons, [s.n.], 1984. 263 p.

RAMOS, L. R. M.; PITELLI, R. A. Efeitos de diferentes períodos de controle da comunidade infestante sobre a produtividade da cultura do milho. Pesquisa Agropecuária Brasileira, v. 29, n. 10, p. 1523-1531, 1994.

RITCHIE, S. W.; HANWAY, J. J.; BENSON, G. O. How a corn plant develops. Ames: Iowa State University of Science and Technology, Cooperative Extension Service, 1993. 22 p. (Special Report, 48)

ROSSI, I. H. et al. Interferência das plantas daninhas sobre algumas características agronômicas e produtividade de sete cultivares de milho. Planta Daninha, v. 14, n. 2, p. 134-148, 1996.

WILSON, R. G.; WESTRA, P. Wild proso millet (Panicum miliaceum) interference in corn (Zea mays). Weed Science, v. 39, n. 2, p. 217-220, 1991.

ZAGONEL, J.; VENÂNCIO, W. S.; KUNZ, R. P. Efeito de métodos e épocas de controle das plantas daninhas na cultura do milho. Planta Daninha, v. 18, n. 1, p. 143-150, 2000. 